\title{
(IN) DISCIPLINA NO ENSINO MÉDIO INTEGRADO DO INSTITUTO FEDERAL DO MARANHÃO: UM OLHAR PEDAGÓGICO SOBRE AS NORMAS
}

\author{
Hélis Regina de Sousa Costa*; Paula Francineti de Araújo Tavares \\ *E-mail: helis.costa@ifma.edu.br \\ Instituto Federal de Educação, Ciência e Tecnologia do Maranhão \\ DOI: $10.15628 /$ rbept.2020.9650
}

Artigo submetido em: mar/2020 e aceito em: abr/2020

\begin{abstract}
RESUMO
Este artigo tem como objetivo analisar as contribuições das normas disciplinares para a formação humana integral dos discentes do ensino médio integrado ao técnico do Instituto Federal do Maranhão (IFMA). Para isso, realizou-se pesquisa documental sobre a Resolução № 0032/2009, que trata do uniforme escolar, e a Resolução № 009/2014, referente ao regimento disciplinar discente. A análise fundamentou-se essencialmente nos conceitos de Karl Marx e Friedrich Engels sobre omnilateralidade e politecnia, na ideia de escola unitária de Antonio Gramsci e na abordagem de Michel Foucault sobre disciplina, além de outros teóricos que com eles dialogam. Os resultados da pesquisa revelaram que as normas disciplinares discentes do IFMA não contribuem para a formação humana integral visto que têm caráter modelador de conduta, com ênfase na padronização, na vigília e na punição.
\end{abstract}

Palavras-chave: Normas disciplinares. Formação humana integral. Ensino médio integrado.

\section{(IN) DISCIPLINE IN THE INTEGRATED EDUCATION OF THE FEDERAL INSTITUTE OF MARANHÃO:}

\section{A PEDAGOGICAL VIEW ON STANDARDS}

\begin{abstract}
This article aims to analyze the contributions of disciplinary norms to the integral human formation of high school students integrated to the technician of the Federal Institute of Maranhão (IFMA). To this end, a documentary research was carried out on Resolution No. 0032/2009, which deals with school uniform, and Resolution No. 009/2014, concerning student disciplinary rules. The analysis was essentially based on Karl Marx and Friedrich Engels' concepts of omnilaterality and polytechnics. Antonio Gramsci's idea of unitary school and Michel Foucault's approach to discipline, as well as other theorists who dialogue with them. The research results revealed that the IFMA student disciplinary norms do not contribute to the integral human formation since they have a behavioral modeling character, with emphasis on standardization, vigilance and punishment.
\end{abstract}

Keywords: Disciplinary Rules. Integral human formation. Integrated high school. 


\section{INTRODUÇÃO}

Este artigo tem como objetivo analisar as contribuições das normas disciplinares para a formação humana integral dos discentes do ensino médio integrado ao técnico do Instituto Federal do Maranhão (IFMA). Para isso, busca-se discutir sobre as concepções de disciplina e o paradigma de educação que defendem, refletir sobre o princípio da formação humana integral no contexto do ensino médio integrado ao técnico, bem como identificar o que as normas disciplinares regulamentam.

A análise fundamenta-se essencialmente nos conceitos de Karl Marx e Friedrich Engels sobre omnilateralidade e politecnia, na ideia de escola unitária de Antonio Gramsci e na abordagem de Michel Foucault sobre disciplina, além de outros teóricos que com eles dialogam.

É importante destacar que as normas estão presentes em nossa vida cotidiana, nos grupos sociais dos quais fazemos parte como família, trabalho, escola e na sociedade de forma geral, regendo as relações interpessoais, institucionais, procedimentais, dentre outras. Assim, as normas disciplinares discentes visam regulamentar a convivência dos educandos no ambiente escolar.

Contudo, essa regulamentação deve buscar a formação de sujeitos críticos, criativos, responsáveis, autônomos e emancipados, isto é, deve contribuir para a formação humana integral dos discentes, do contrário serão formados sujeitos passivos, incapazes de compreenderem as contradições da realidade na qual estão inseridos. Para Ciavatta (2014), a formação humana integral visa não apenas superar a dualidade entre teoria e prática, formação para o trabalho manual e para o trabalho intelectual, mas superar as contradições da sociedade capitalista, em defesa da democracia e da escola pública.

Com a criação dos Institutos Federais em 2008 pela Lei № 11.892, tendo como um dos seus objetivos a oferta de ensino médio integrado ao técnico, no percentual de $50 \%$ de suas vagas, conforme está previsto no artigo $8^{\text {o }}$ da referida lei, essa etapa da educação básica começa a ser percebida como uma travessia para a formação humana integral, a qual se concretizará plenamente em uma sociedade onde não haverá divisão de classes e todos poderão ter a mesma educação e as mesmas oportunidades, o que é inviável na sociedade capitalista (MOURA, 2013).

Assim, na perspectiva individual, a formação humana integral visa formar sujeitos autônomos e emancipados, mas para quê? Para que possam atuar na sociedade de forma responsável e comprometida com a superação do sistema capitalista e com a construção de um sistema social verdadeiramente justo e igualitário para todos, o que constitui a perspectiva coletiva da formação humana integral. 
Nesse contexto, o presente trabalho pretende encontrar resposta para a questão: quais as contribuições das normas disciplinares para a formação humana integral dos discentes do ensino médio integrado ao técnico do Instituto Federal do Maranhão? Para tanto, apresenta-se o referencial teórico que fundamenta o estudo, a metodologia adotada para a realização da pesquisa, os resultados e discussões obtidos a partir das análises realizadas, as considerações finais e as referências.

\section{REFERENCIAL TEÓRICO}

Esse artigo fundamenta-se essencialmente nos conceitos de Karl Marx e Friedrich Engels sobre omnilateralidade, politecnia; na ideia de escola unitária de Antonio Gramsci; na análise de Michel Foucault sobre disciplina; nas ideias de Marise Ramos, Maria Ciavatta e Dante Moura sobre ensino médio integrado e formação humana integral; na pedagogia histórico-crítica de Demerval Saviani, bem como em outros autores que tratam do tema em discussão.

As contribuições dos autores supracitados constam nas três subseções que serão apresentadas a seguir: as concepções de disciplina: qual ideal de educação defendem?, formação humana integral: princípio do ensino médio integrado ao técnico e Normas disciplinares discentes do IFMA: o que estabelecem?

\subsection{As concepções de disciplina: qual paradigma de educação defendem?}

A análise realizada por Michel Foucault sobre disciplina, em sua obra Vigiar e Punir, ajuda-nos a compreender qual o propósito inicial dessa técnica comportamental e de que forma a escola absorveu seus princípios. Embora a disciplina seja retratada por Foucault inicialmente no contexto do nascimento da prisão, com o fim do suplício, tendo em vista domesticar os prisioneiros, o filósofo faz também várias relações com outras instituições disciplinares como escolas, hospitais e indústrias destacando as semelhanças no tratamento da questão disciplinar.

Segundo Foucault (1987), "houve durante a época clássica uma descoberta do corpo como objeto e alvo de poder" (FOUCAULT, 1987, p. 117) que se estruturou e se expandiu posteriormente, na modernidade, compreendida por este como um período de transição do séc. XVII para o séc. $\mathrm{XVIII}$. Com isso, buscava-se manipular, modelar e multiplicar as forças dos corpos, tornando-os dóceis e úteis, através do que ele definiu como "disciplina".

Nessa perspectiva, a disciplina corresponde aos [...] "métodos que permitem o controle minucioso das operações do corpo, que realizam a 
sujeição constante de suas forças e lhes impõem uma relação de docilidadeutilidade." (FOUCAULT, 1987, p. 118). Segundo o autor, esse controle era possível através do uso de três instrumentos simples: vigilância hierárquica, sansão normalizadora e exame.

Através da vigilância hierárquica, de acordo com o filósofo, o exercício da disciplina acontece pelo jogo do olhar, isto é, o indivíduo sabendo que está sendo constantemente vigiado pelo seu superior tenderá a obedecê-lo, por medo da punição. A sansão normalizadora, por sua vez, funciona como um modelo reduzido de tribunal, visto que tem a função de regulamentar 0 comportamento dos indivíduos, exercendo sobre eles uma pressão constante que os obriguem a comportar-se conforme os padrões estabelecidos, punindo aqueles que os descumprirem. Já o exame combina as técnicas da vigilância hierárquica e as da sansão normalizadora para realizar registros de cada indivíduo, com detalhes e minúcias de seus comportamentos, visando à medição, à classificação e à punição dos sujeitos.

Identifica-se, com isso, que a disciplina visava moldar os sujeitos, adestrá-los, como se fossem objetos que precisassem ter uma utilidade externa a ele, desconsiderando a subjetividade, os interesses e até mesmo a dignidade humana. A partir dessa observação é importante questionar: por que fabricar sujeitos dóceis e úteis? Para substituir o princípio da retirada-violência pelo da suavidade-produção-lucro, isto é, a disciplina buscava ajustar a multiplicidade de homens e a multiplicidade dos aparelhos de produção, dos saberes e aptidões sem o uso da força e de forma eficiente (FOUCAULT, 1987).

E quais os impactos da disciplina sobre a escola do século XVIII? Através dessa técnica surge, a localização imediata ou o quadriculamento, que permite localizar um indivíduo em cada lugar, permitindo a organização dos alunos em fileiras nas salas de aula, nos corredores, nos pátios; a função dos inspetores escolares; a estrutura física organizada em salas justapostas e formando corredores que possibilitem a observação dos comportamentos; a posição de cada aluno em relação a cada tarefa e prova; o alinhamento das classes por idade umas depois das outras; a sucessão dos assuntos ensinados segundo uma ordem de dificuldade crescente, determinação de lugares individuais para cada aluno, a sanção, a distribuição das atividades no tempo, a obediência inquestionável ao professor e o olhar classificador deste, o que torna a escola não apenas um máquina de ensinar, mas de vigiar, classificar, recompensar (FOUCAULT, 1987).

Dessa forma, a disciplina escolar servia para manter a ordem e controlar a criança desde cedo, preparando-a para servir às ideias difundidas no século $\mathrm{XVIII}$, através do silêncio e da submissão do aluno às ordens do professor, considerado o detentor do conhecimento e dos ensinamentos sobre as condutas adequadas para se viver na sociedade capitalista, em que garantindo-se a obediência dos indivíduos economiza-se tempo e aumenta-se a produção (REBELO, 2011).

Infelizmente essa ainda é a realidade de boa parte das escolas contemporâneas herdeiras de uma formação centrada no professor, 
propedêutica e modeladora, em que não se valoriza a liberdade de expressão, a criatividade e a problematização das questões sociais. A essa concepção de educação em que o professor é o centro do processo ensino-aprendizagem e responsável pelo depósito de conhecimento junto aos alunos, Freire (1997) denomina de educação bancária.

Sendo assim, a disciplina como técnica de adestramento de pessoas defende $o$ ideal de educação bancária ao fabricar sujeitos dóceis e úteis para atender as demandas do sistema de produção capitalista. Contudo, Rebelo destaca que "a disciplina também pode ser entendida como construção interna que colabora com a busca da autonomia intelectual, fator importante para a libertação do homem" (REBELO, 2011, p. 53).

Isso implica em uma concepção de educação baseada no respeito a todas as visões de mundo, na esperança e troca de experiência entre os envolvidos mediada pelo diálogo, elemento indispensável em uma educação libertadora (FREIRE, 1979). Assim, o diálogo constitui-se em prática educativa que deve ocorrer em uma relação horizontal em que tanto educador como educando busquem conhecimento.

$\mathrm{Na}$ concepção de educação libertadora a disciplina é pedagógica e entendida como organização, visto que surge da autoridade, compromisso e competência docentes, sem excluir a participação e o compromisso dos discentes nesse processo, colaborando para a autodisciplina e autonomia destes, mediada pelo diálogo (REBELO, 2011).

A pedagogia histórico-crítica defendida por Saviani (2013) também critica a educação bancária, chamada por ele de educação tradicional, e vai além da educação libertadora de Paulo Freire ao colocar no cerne da questão educativa "a compreensão da história a partir do desenvolvimento material, da determinação das condições materiais da existência humana, com base na teoria marxista" (SAVIANI, 2013, p. 88).

A ideia defendida pelo autor é desvelar as contradições presentes na sociedade capitalista e, consequente, na educação escolar tendo em vista a superação das desigualdades sociais. Nesse contexto, a escola tem uma função especificamente educativa em que o conhecimento sistematizado deve ser socializado pra todos.

Ao falar de contradições refere-se a ideia de movimento, de tensão, de dialética que visa superar uma dada realidade. Segundo Hegel "a contradição é a raiz de todo movimento e vitalidade; pois só ao conter em si uma contradição, uma coisa se move, tem impulso e atividade" (HEGEL, 1993, p. 72 apud VASCONCELLOS, p. 112).

Assim sendo, a disciplina na perspectiva da pedagogia histórico-crítica, visa mediar a tensão entre autoridade e liberdade, conservação e transformação, através da postura dialética do professor que consiste em

Conservar a tensão interna (caráter contraditório da realidade); quer dizer, quando estamos sendo "porto seguro" - orientando, dirigindo, expondo- temos de nos questionar: "até que ponto não deveríamos ser 'mar aberto', incentivando, provocando a participação, a iniciativa, a 
criatividade do grupo?" Quando estamos sendo "mar aberto", precisamos tensionar: "até que ponto não teríamos de ser "porto seguro', amarrar sistematizar, intervir?" Alimentar esse tensionamento interno é a arte do professor para gerir a questão da disciplina (VASCONCELLOS, 2009, p. 115-116).

Isso significa que as contradições estão em constante movimento e que cabe ao professor compreender a dinâmica desse processo dialético, uma vez que é o mediador do processo ensino-aprendizagem. Esse não é um desafio para o qual haja receita pronta, mas é necessário gerir a situação no caso concreto, com compromisso social, que consiste na capacidade de agir e refletir, transformando a realidade, o que faz do homem um ser de práxis (FREIRE, 1979).

Ainda sobre as concepções de disciplina, Vasconcellos (2009) destaca que existem dois sentidos distintos dessa técnica: o sentido epistemológico ou intelectual referente a saberes organizados e o sentido ético e moral, relacionado a princípios de conduta individual ou coletivo. É nesse último sentido que a disciplina está sendo tratada nesse trabalho, porém é importante destacar que ambos os sentidos são indissociáveis, uma vez que "precisamos da disciplina (enquanto ordem de saberes) para compreender e fazer disciplina (enquanto postura)" (VASCONCELLOS, 2009, p. 90).

Também é oportuno destacar que a abordagem disciplinar que contribui para a formação humana integral, entendida como formação do homem em todas as suas dimensões é aquela que estimula a autonomia, o autogoverno e a autodisciplina tendo em vista a participação ativa dos sujeitos no contexto social, o que é viabilizado através da pedagogia histórico-crítica, sendo por essa razão a concepção defendida nesse texto.

Diante do exposto, é possível identificar que não há como falar das concepções de disciplina desconectadas de uma visão de educação e sociedade. Assim, respondendo ao questionamento inicial proposto no título da subseção, a disciplina pode servir ao paradigma de educação tradicional, bancário, quando visa moldar comportamentos, pode estar contribuindo para uma educação libertadora quando fundamenta-se no diálogo, pode, ainda, ser instrumento que vise a transformação social, a partir da pedagogia históricocrítica, dentre outras possibilidades possíveis, o que vai definir a abordagem disciplinar será a postura do professor e da escola frente ao compromisso social que the cabe. 


\subsection{Formação humana integral: princípio do ensino médio integrado ao técnico}

Ao compreender que a disciplina, capacidade de se autogovernar para entender a realidade e nela atuar, contribui para a formação humana integral faz-se necessário realizar algumas reflexões: Qual a origem do termo formação humana integral? O que ele significa na atualidade? É possível alcançá-la na educação escolar brasileira? Quais as dificuldades encontradas e os avanços atingidos na perspectiva de sua realização? Qual o papel do ensino médio integrado ao técnico nesse contexto?

De acordo com Ciavatta (2014), a gênese da formação humana integral está na educação socialista que pretendia ser omnilateral, isto é formar o ser humano na sua integralidade mental, física e tecnológica, unindo instrução e trabalho, como defendeu Marx ao falar sobre trabalho juvenil e infantil no texto Instruções para os Delegados do Conselho Geral provisório: as diferentes questões, escrito em 1866:

[...] nenhum pai nem nenhum patrão deveria ser autorizado a usar trabalho juvenil, excepto quando combinado com educação. Por educação entendemos três coisas:

Primeiramente: Educação mental.

Segundo: Educação física, tal como é dada em escolas de ginástica e pelo exercício militar.

Terceiro: Instrução tecnológica, que transmite os princípios gerais de todos os processos de produção e, simultaneamente, inicia a criança e o jovem no uso prático e manejo dos instrumentos elementares de todos os ofícios (p. 5).

A partir do fragmento de texto acima citado, observa-se que Marx não era a favor do trabalho juvenil, mas se este fosse necessário deveria ser combinado com uma educação que pudesse formar o indivíduo em suas múltiplas dimensões, omnilateral.

A omnilateralidade em Marx corresponde, portanto, ao desenvolvimento total do ser humano, em todos os sentidos, das faculdades e das forças produtivas, das necessidades e da capacidade de sua satisfação, em oposição ao homem alienado e unilateral da sociedade capitalista, tendo em vista a revolução proletária (MANACORDA, 2007).

Posteriormente à Marx, no século XX, Gramsci defende a ideia de escola unitária ao sustentar que à esta [...] "deveria se propor a tarefa de inserir os jovens na atividade social, depois de tê-los levado a um certo grau de maturidade e capacidade, à criação intelectual e prática e a uma certa autonomia na orientação e iniciativa" (2000, p. 36). 
Observa-se, com isso, que Gramsci não descarta a união entre instrução e trabalho proposta por Marx, mas que enfatiza o aspecto humanista da escola propondo que após a educação geral fosse ofertada a educação profissional.

Sobre esse aspecto, Moura, Lima Filho e Silva (2015) destacam que a formação humanista proposta por Gramsci não se confunde com a forma liberal, voltada para o ensino memorístico, mas visa contribuir para o desenvolvimento humano intelectual e prático e para a compreensão da totalidade social, tendo o trabalho como princípio educativo.

A concepção de trabalho, nesse contexto, não está relacionado à emprego (trabalho assalariado), mas à sua concepção ontológica e histórica que constitui e educa o homem, a partir do momento em que este interage conscientemente com a natureza, transformando-a, para atender suas necessidades vitais e, consequentemente, gerando conhecimento (RAMOS, 2014).

Atualmente, a formação omnilateral, politécnica, capaz de se concretizar em uma escola unitária, também é conhecida como formação humana integral, sendo esses termos considerados sinônimos, uma vez que têm como objetivo a educação do sujeito em suas múltiplas dimensões (SAVIANI, 2013).

Embora tenha havido alguns avanços na legislação brasileira ao reconhecer a importância da formação humana integral, a sua concretização ainda é uma utopia, um sonho, que tem no ensino médio integrado o seu germe. Isso se deve ao fato de vivermos em uma sociedade capitalista governada por interesses de pequenos grupos que pouco se relacionam com igualdade de direitos, educação pública de qualidade, democracia de fato e de direito.

O ensino médio integrado ao técnico (EMI) é resultado de muitas lutas e contradições ocorridas ao longo da história da educação brasileira. Conforme Ramos (2014), na década de 90 houve a separação entre educação geral e profissional legitimada pelo Decreto 2.208/97, que foi derrubado pelo Decreto $5.154 / 2004$, numa tentativa de integração curricular entre as duas áreas. Os termos desse Decreto foram incorporados à Lei 11.741/2008 que alterou a Lei de Diretrizes e Bases da Educação (Lei 9394/96) incluindo a possibilidade de articulação entre educação profissional e geral, conforme está previsto em seu art. 36-C, I, o que representa uma possibilidade de alcançarmos a formação humana integral, politécnica e omnilateral em uma época futura. Porém, pode ser também instrumento que alimenta o sistema capitalista, caso a profissionalização seja adotada em sentido estrito, visando apenas atender as demandas do mercado de trabalho.

Posto isto, busca-se analisar as normas disciplinares discentes do Instituto Federal do Maranhão no intuito de identificar de que forma contribui ou não para a formação humana integral, objetivo maior da Educação Profissional e Tecnológica, conforme será abordado a seguir. 


\subsection{Normas disciplinares discentes do IFMA: o que estabelecem?}

O Instituto Federal de Educação, Ciência e Tecnologia do Maranhão (IFMA) regulamenta a postura disciplinar dos seus discentes por meio de duas resoluções: $N^{\circ}$ 032/2009 e $N^{\circ}$ 009/2014, que foram aprovadas por seu Conselho Superior (CONSUP), órgão máximo consultivo e deliberativo composto por representantes de todos os segmentos da comunidade escolar, escolhidos por eleição, e presidido pelo reitor (RESOLUÇÃO № 30, 2014).

Dentre as atribuições do CONSUP previstas no Art. $5^{\circ}$ da Resolução $n^{\circ}$ 30 de 2014, destaca-se: "IV - aprovar o projeto político-pedagógico, a organização didática, regulamentos internos e normas disciplinares" (p. 8, grifo nosso), razão pela qual esse órgão é responsável pela regulamentação do comportamento dos discentes no âmbito do IFMA.

No tocante às normas disciplinares, destaca-se que a Resolução $N^{\circ}$ 032/2009 regulamenta o uniforme escolar, prevendo inicialmente, a obrigatoriedade do seu uso por todos os discentes regularmente matriculados em cursos técnicos, nas formas integrada, concomitante e subsequente ao ensino médio e PROEJA, sendo facultativo aos alunos da graduação e pósgraduação e aos alunos do turno noturno.

A norma inclui como componentes do fardamento a calça jeans azul escura, sem detalhes, a camiseta com a identificação da Instituição, tênis nas cores preta, azul escuro e cinza ou sapato fechado (na cor preta) e meia; define, ainda, uniforme diferenciado para as práticas esportivas e possibilidade de exigência de bata em outras aulas realizadas nos laboratórios, no campo ou visitas técnicas.

No parágrafo único do artigo $3^{\circ}$ da resolução supracitada está prevista a suspensão das atividades escolares em caso de desobediência às normas de uso do uniforme, até que a situação seja regularizada.

A Resolução $N^{\circ}$ 009/2014, por sua vez, refere-se ao regimento disciplinar discente, por tanto, abrangendo não apenas o controle do uniforme enfatizado pela resolução anteriormente citada, mas toda a conduta daqueles que estão regularmente matriculados nos cursos e programas do IFMA, seja na forma presencial ou à distância.

$\mathrm{O}$ art. $1^{\circ}$ da norma dispõe que seus princípios balizadores são a equidade e a justiça, tendo em vista a ampla formação humana. Assim, tem como finalidade definir e classificar os atos indisciplinares, as sanções e os critérios de sua aplicabilidade, garantidos aos discentes o direito ao contraditório e à ampla defesa.

Nessa perspectiva, os atos são classificados, conforme a natureza e a gravidade, em leves, médios, graves e gravíssimos, sendo definidos como: 
Art. $9^{\circ}$ Os atos indisciplinares de natureza leve são os que afetam os padrões éticos, morais e pedagógicos e não comprometem 0 desenvolvimento das atividades educativas.

Art. 10 Os atos indisciplinares de natureza média são os que afetam os padrões éticos, morais e pedagógicos e comprometem 0 desenvolvimento das atividades educativas.

Art. 11 Os atos de natureza grave são os que comprometem os padrões éticos, morais e os bons costumes, bem como o desenvolvimento das atividades educativas.

Art. 12 Os atos de natureza gravíssima são os que ofendem a dignidade dos servidores públicos no exercício da função, assim como os pares discentes e os terceiros contratados ou não, atentatória às instituições ou ao Estado e que comprometem o projeto pedagógico da Instituição afetando gravemente os padrões de disciplina, ética, moral e bons costumes (RESOLUÇÃO OO9, 2014, p. 5).

Para cada natureza de ato indisciplinar a norma acima destacada elenca um rol de situações passíveis de ocorrência. Os alunos que praticarem tais atos poderão sofrer, dependendo da gravidade, advertência oral, advertência escrita, suspensão assistida e desligamento da Instituição, de caráter educativo, tendo em vista a preservação da disciplina escolar, elemento indispensável à formação integral do discente (RESOLUÇÃO 009, 2014).

O contraditório e a ampla defesa estão garantidos aos alunos nos casos de apuração de responsabilidade que acontecerá por meio de Processo Disciplinar Sumário, quando se tratar de prática de atos indisciplinares de natureza leve e média e através de Processo Disciplinar Ordinário, para casos de natureza grave e gravíssima, sendo que os processos serão conduzidos por comissões específicas.

\section{METODOLOGIA}

A pesquisa realizada para a elaboração desse artigo, quanto ao objetivo, é do tipo descritiva-explicativa, uma vez que visa conhecer e explicar uma dada realidade (MACÊDO; EVANGERLANDY, 2018), qual seja, as normas disciplinares discente do IFMA e sua relação com a formação humana integral

Para isso, utilizou-se como método científico o materialismo históricodialético cujo objetivo é interpretar a realidade a partir da teoria marxista. De acordo com Leite (2017), o referido método é dialético porque [...] "parte da análise de polos contraditórios que em um confronto superam momento anterior, produzindo, através da própria ação sobre a realidade, uma nova realidade pensada" (p. 847). O caráter histórico, por sua vez, consiste em 
revelar a dimensão diacrônica da realidade objetiva permitindo observá-la como processo em desenvolvimento.

Assim, busca-se compreender as contradições das normas disciplinares discentes tendo em vista a educação humana integral, omnilateral, politécnica, levando-se em conta o contexto no qual foram elaboradas e o atual, buscando evidências sobre qual tipo de sujeito está sendo educado.

Quanto ao procedimento, foi adotada a pesquisa documental visto que busca informações a partir de fontes primárias que ainda não tiveram tratamento analítico (SEVERINO, 2016). As fontes utilizadas foram a Resolução 032/2009 e Resolução 009/2014, documentos oficiais do IFMA.

A abordagem utilizada foi predominantemente qualitativa, uma vez que "[...] busca-se interpretar os fenômenos ao invés de provar hipóteses por quantificações estatísticas" (MACÊDO; EVANGERLANDY, 2018, p. 73), mas fez-se uso de alguns dados numéricos para subsidiar a análise.

Como técnica de coleta de dados foi utilizada a análise documental da Instituição pesquisada referente às normas disciplinares discentes. De acordo com Ludke e André (2018), a análise documental é uma importante técnica de abordagem qualitativa que, combinada com outras técnicas, contribui para o alcance de novos elementos relacionados ao problema pesquisado.

Os dados coletados foram interpretados à luz dos autores que compõem o referencial teórico da pesquisa e através da análise de conteúdo, entendida como "método de investigação do conteúdo simbólico das mensagens" (LUDKE; ANDRÉ, 2018, p. 48), tendo como unidade de análise os artigos das normas e seus desdobramentos.

\section{RESULTADOS E DISCUSSÕES}

Antes de aprofundarmos a análise sobre as normas disciplinares discentes do IFMA faz-se necessário contextualizá-las. Essas normas existem para atender a demanda disciplinar discente do Instituto Federal do Maranhão, definida como instituição de educação superior, básica e profissional, pluricurricular e multicampi, especializada na oferta de educação profissional e tecnológica, com base na conjugação de conhecimentos técnicos e tecnológicos (LEI № 11.892, 2008).

A criação dos Institutos Federais passou por um processo de muito debate político, econômico, pedagógico e filosófico que data desde sua origem quando da criação das Escolas de Aprendizes Artífices em 1909, pelo presidente Nilo Peçanha, até os dias atuais (MEC, 2016). De um lado defendese uma escola de formação humana integral que visa superar a dualidade histórica entre teoria e prática e, do outro lado, a formação profissional para atender as demandas do mercado de trabalho (RAMOS, 2014). 
De acordo com a autora acima citada, desde a década de 90, com as reformas educacionais impostas, aliadas à ideologia da empregabilidade, que obriga o trabalhador a qualificar-se cada vez mais para ocupar uma vaga no mercado de trabalho e nele permanecer, a pedagogia das competências tem sido a diretriz político-pedagógico do projeto educacional brasileiro, cujo o princípio é a adaptabilidade do sujeito às mudanças socioeconômicas do capitalismo.

Nesse contexto, é relevante questionar: as normas disciplinares discentes do IFMA contribuem para a formação humana integral ou visam à adaptabilidade do indivíduo às demandas mercadológicas do sistema capitalista? A análise que se faz a seguir busca encontrar resposta para esse questionamento.

A Resolução 032/2009 trata exclusivamente de uniforme e está vigente há uma década, sem alterações. Nela encontra-se características meramente disciplinadoras como obrigatoriedade, padronização e sanção, caso haja seu descumprimento.

No tocante à obrigatoriedade, a norma inclui todos os alunos regularmente matriculados no IFMA, exceto os que estudam à noite e os do ensino superior. Nesse ponto, encontram-se alguns problemas: se for marcada aula extra para os alunos do turno noturno pela manhã ou à tarde terão que comparecer fardados? Os alunos do ensino superior que estudam pela manhã e à tarde misturam-se aos alunos do ensino médio integrado, por exemplo, como será feito o controle quanto ao uso do uniforme? Qual o sentido pedagógico desse controle? Considerando que o IFMA é uma instituição pública e seu aluno é obrigado a usar uniforme, a Instituição fornece todos os itens de forma gratuita (camiseta, calça jeans azul, tênis, vestimenta da prática esportiva, bata para uso nos laboratórios)?

Para Saviani (2013), a escola tem função especificamente educativa, ligada ao conhecimento, por isso deve socializar os conhecimentos acumulados pela humanidade destacando seus determinantes históricos. Nessa perspectiva, a obrigatoriedade do uniforme é uma questão secundária diante da função principal da escola que é a socialização do saber escolar, isto é, do "saber dosado e sequenciado para efeitos de sua transmissãoassimilação, no espaço escolar, ao longo de um tempo determinado" (SAVIANI, 2013, p. 18) e precisa ser considerada a partir desse entendimento.

Quanto à padronização, chama a atenção o fato de a norma especificar inclusive as cores do tênis (branca, preta, azul-escura ou cinza). Qual a relevância dessa determinação para o processo ensino-aprendizagem? Qual o objetivo da padronização se cada indivíduo é diferente? Ao apresentar esses questionamentos não se pretende defender o uso de vestimenta que atente contra a moral e cause constrangimentos no ambiente escolar, mas refletir sobre o seu significado diante das questões pedagógicas e filosóficas que permeiam a educação pública. 
Segundo Percília (2019), o uso do uniforme escolar tem sua origem no exército, uma das primeiras instituições a adotar uma vestimenta única para todos os seus membros, e foi criado para simbolizar as cores, o nome, a tradição e o símbolo da escola. Assim, os alunos uniformizados deveriam manter um comportamento exemplar e zelar pela imagem das instituições, mesmo fora delas. A afirmação da autora converge com o pensamento de Foucault (1987), uma vez que este destaca a aproximação da escola com o exército, em virtude das técnicas disciplinares adotadas por ambos, tendo em vista moldar sujeitos, tornando-os obedientes e apropriados.

Sobre a sansão prevista em caso de descumprimento das regras do uniforme escolar que consiste na suspensão do aluno de suas atividades pedagógicas até a regularização da situação, é necessário fazer algumas observações: o aluno descumpriu as regras do fardamento por afronta ou por outro motivo? $O$ uso do uniforme faz sentido para o aluno? Suspender o aluno sem dar-Ihe o direito de defesa não seria uma atitude autoritária? Qual benefício pedagógico a suspensão traria ao aluno? A punição, nesse contexto, educa ou obriga o cumprimento da regra por medo de sua incidência?

Para Aquino (2016), o descumprimento das regras "pode estar indicando o impacto do ingresso de um novo sujeito histórico, com outras demandas e valores, numa ordem arcaica e despreparada para absorvê-lo plenamente" (AQUINO, 2016, p.45). Isso aponta para a necessidade de a escola se reinventar e buscar atender a demanda desse novo homem, compreendendo-o e contribuindo para sua formação integral. O que não significa, contudo, que a escola deverá tornar-se refém dos alunos, mas que deve construir com eles uma relação dialógica e horizontal (FREIRE, 1979), cujo o objetivo seja a apropriação de conhecimento e a compreensão da realidade na qual estão inseridos.

Concluída a análise sobre a Resolução 032/2009, far-se-á a análise sobre a Resolução 009/2014 que trata sobre o regimento disciplinar discente. Nela estão incluídas normas quanto ao uniforme escolar e todas as demais relacionadas ao comportamento do discente do IFMA. A Resolução no 126/2013 foi a primeira norma a aprovar o regimento disciplinar discente do IFMA, porém foi revogada pela resolução atual. De 2008, ano de criação dos Institutos Federais, até meados de 2013 não foram encontrados registros de norma disciplinar discente que regulamentasse o comportamento dos discentes do Instituto Federal do Maranhão. Acredita-se que uma pesquisa de campo poderia identificar os motivos dessa ausência e a forma como a disciplina era tratada antes da elaboração da norma, o que não será tratado neste trabalho, visto que trata-se apenas de uma pesquisa documental.

$\mathrm{Na}$ resolução vigente encontra-se um rol de situações previstas como atos indisciplinares classificados quanto à natureza (leve, média, grave ou gravíssima). Segundo a norma, "atos indisciplinares são quaisquer violações dos preceitos de ética, dos deveres e obrigações escolares, das regras de 
convivência social e dos padrões de comportamento atribuídos aos alunos, em função do sistema de ensino" (RESOLUÇÃO 009, 2014, p. 4). Essa definição está associada à ideia de ajustamento social, adequação de conduta, que pouco contribui para a formação do sujeito em suas múltiplas dimensões e vai de encontro à compreensão de indisciplina numa perspectiva histórico-crítica, segundo a qual a

Indisciplina, então, seria sintoma de injunção da escola idealizada e gerida para um determinado tipo de sujeito e sendo ocupada por outro. [...] Denotaria a tentativa de rupturas, pequenas fendas em um edifício secular como é a escola, potencializando assim uma transição institucional, mais cedo ou mais tarde, de um modelo autoritário de conceber e efetivar a tarefa educacional para um modelo menos elitista e conservador (AQUINO, 2016, p. 45)

Dessa forma, a indisciplina não seria ausência de disciplina, mas a manifestação de resistência quanto àquilo que está posto e que não tem significado para o aluno.

A partir do rol de situações elencadas na norma foi possível classificálas em dez categorias. Assim, os atos indisciplinares previstos na resolução ora analisada foram classificados conforme demonstrado no gráfico abaixo:

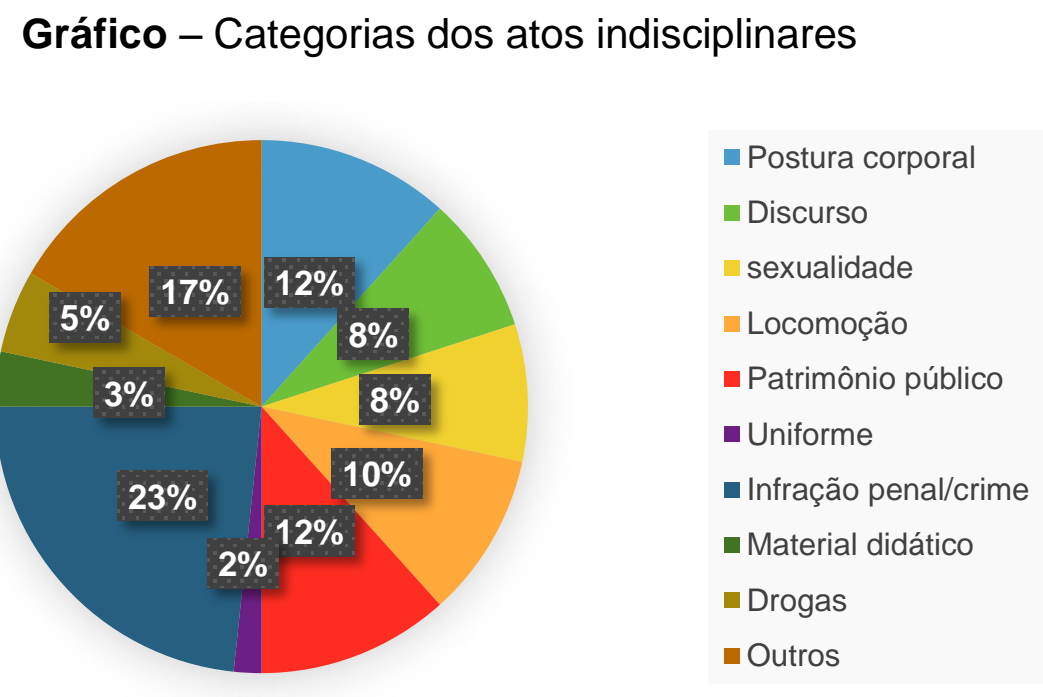

Fonte: autora, 2019

O percentual que cabe a cada categoria especificada no gráfico diz respeito à relação desta com a totalidade de atos elencados na norma. Isso quer dizer que do total de sessenta atos indisciplinares, $12 \%$ correspondem à postura corporal, $8 \%$ ao discurso, $8 \%$ à sexualidade, $10 \%$ à locomoção, $12 \%$ ao patrimônio público, $2 \%$ ao uniforme, $23 \%$ à infração penal/crime, 3\% ao 
material didático, $5 \%$ às drogas e $17 \%$ à outros atos que não se enquadram em nenhuma das categorias anteriormente citadas, como atos relacionados ao meio ambiente, estacionamento de veículos, objetos pessoais, horários, prática de comércio, tecnologia da informação e comunicação.

Para que se compreenda quais atos indisciplinares estão incluídos nas categorias supracitadas será apresentado a seguir um quadro que destaca alguns exemplos.

Quadro - Atos indisciplinares previstos na Resolução № 009/2014

\begin{tabular}{|c|c|}
\hline CATEGORIAS & EXEMPLOS \\
\hline Postura corporal & $\begin{array}{c}\text { Sentar no colo do(a) colega e deitar nos ambientes } \\
\text { escolares (Art. } 13, \mathrm{XV} \text { ) }\end{array}$ \\
\hline Discurso & $\begin{array}{c}\text { Dirigir a seus pares, servidores públicos, terceiros } \\
\text { contratados ou não e/ou visitantes de maneira } \\
\text { desrespeitosa (Art. 14, VI) }\end{array}$ \\
\hline Sexualidade & $\begin{array}{c}\text { Assediar ou cometer abuso sexual contra seus pares e } \\
\text { servidores (Art. } 16, \mathrm{XI}) .\end{array}$ \\
\hline Locomoção & $\begin{array}{l}\text { Transitar ou fazer uso de espaços ou vias de acesso } \\
\text { não permitidas ao corpo discente (Art. 13, V). }\end{array}$ \\
\hline Patrimônio Público & $\begin{array}{c}\text { Ingressar, acionar ou utilizar instalações, máquinas ou } \\
\text { equipamentos agrícolas dentre outros bens da mesma } \\
\text { natureza do Instituto, ou fazer uso indevido, sem } \\
\text { autorização da autoridade competente, inclusive com } \\
\text { visitantes (Art. 14, XIII). }\end{array}$ \\
\hline Uniforme & $\begin{array}{l}\text { Transitar na instituição sem uniforme em horário de } \\
\text { atividades escolares (Art. 13, XIV). }\end{array}$ \\
\hline Infração penal/crime & Furtar ou roubar bens móveis (Art. 16, II). \\
\hline Material didático & $\begin{array}{c}\text { Comparecer ao ambiente escolar sem levar o material } \\
\text { necessário ou portando objetos não autorizados pela } \\
\text { autoridade competente (Art. 13, III). }\end{array}$ \\
\hline Drogas & $\begin{array}{c}\text { Induzir qualquer pessoa ao uso de substância alcoólica, } \\
\text { tóxica, entorpecente ou produtos alucinógenos no } \\
\text { ambiente escolar (Art. 15, IX). }\end{array}$ \\
\hline Outros & $\begin{array}{c}\text { Infringir normas de uso de recursos de tecnologia da } \\
\text { informação e da comunicação da instituição (Art. 16, } \\
\text { VII). }\end{array}$ \\
\hline
\end{tabular}

Fonte: autora, 2019 
A análise do gráfico e do quadro acima apresentados, para o propósito desse artigo, não está na relação das partes com o todo, ou na especificação dos atos considerados indisciplinares pela Instituição, mas na identificação da essência desses atos. A essência, na perspectiva marxista, é uma categoria de análise do objeto investigado que visa compreendê-lo em sua totalidade, capturando a sua estrutura e dinâmica, a partir de sua aparência, daquilo que está posto, mas indo muito além dela, desvelando todas as contradições (PAULO NETTO, 2011).

Sendo assim, é relevante analisar não apenas quais atos são considerados indisciplinares, mas por que o são. Por que disciplinar, vestimentas, posturas, locomoção, discurso, por exemplo? Qual o significado dessa regulamentação para os discentes? Que tipo de sujeitos serão formados através dessa normatização? Para qual sociedade? São questionamentos que todo educador deve fazer antes de exigir determinados comportamentos de seus alunos, considerando seu "compromisso político para com a sociedade" (FREIRE, 1979).

Com isso, não se está defendo uma educação em que tudo é permitido, mas uma reflexão sobre o significado de disciplina como técnica do detalhe, conforme enfatizava Foucault (1987) ao analisá-la no contexto do século XVIII.

No tocante ao uniforme, destaca-se que foi identificada incoerência entre as normas. Enquanto a Resolução 032/2019 prevê suspensão do discente de suas atividades pedagógicas caso haja descumprimento no uso regular do uniforme, de acordo com o parágrafo único do Art. $3^{\circ}$, a Resolução 009/2014 dispõe que o descumprimento quanto ao uso de uniforme é um ato indisciplinar de natureza leve, passível de advertência escrita e oral, de acordo com os artigos 13 , XIV; 32 e 42 . O que fazer então no caso concreto? Desrespeitando o cumprimento das regras quanto ao uniforme o discente será suspenso, receberá advertência oral ou advertência escrita? A penalidade é realmente necessária no contexto de uma escola pública em que boa parte dos alunos não possui o suficiente para sobreviver? Por que se encontram nessa situação? O que a escola pode fazer diante disso? Precisamos refletir sobre essas questões antes de aplicar qualquer punição.

Quanto ao tratamento dado pela norma aos casos de indisciplina, esta prevê quatro sansões que terão caráter educativo visando a preservação da disciplina escolar: advertência oral, advertência escrita, suspensão assistida e desligamento da Instituição, de acordo com o Art. 19. Analisando as quatro sanções destaca-se que na suspensão assistida, conforme o Art. 22, o aluno é acompanhado pela equipe pedagógica, o que indica a aplicação de uma medida não apenas punitiva, mas educativa. Nas demais sansões, não se identificou caráter pedagógico.

Com essa configuração de norma, na perspectiva da análise de Foucault (1987), a escola funciona como uma prisão, onde os alunos são constantemente vigiados e punidos tendo em vista o adestramento de corpos 
dóceis e úteis. Sendo assim, o processo pelo qual o aluno se submete para apuração de responsabilidade, embora tenha a intenção de garantir o contraditório e a ampla defesa, transforma-se em "[...] um modelo reduzido do tribunal" (FOUCAULT, 1987, p. 149), em que o aluno torna-se réu, a comissão disciplinar corresponde à delegacia que faz o inquérito do aluno e os diretores, representam os juízes que decidem o caso.

Vale ainda destacar que o tempo para conclusão do processo é extenso, sendo de até 20 dias no caso de processo disciplinar sumário (Art. 33) e de até 45 dias, em se tratando de processo disciplinar ordinário (Art. 37). Com isso, faz-se necessário questionar: $O$ que significa, para o discente, receber uma punição após 20 ou 45 dias da prática de um ato dito indisciplinar?

Sobre a formação humana integral, alguns registros foram encontrados na norma, nos artigos 10; $5^{\circ}$, II e 18. De acordo com esses dispositivos, a formação humana integral é um direito do aluno e objetivo do IFMA, razão pela qual a disciplina deve contribuir para a sua concretização.

Contudo, observou-se que os demais dispositivos da norma enfatizam a adequação dos alunos a um modelo ideal de homem, submisso, cumpridor de horários, padronizado, silencioso e sujeito a punições caso não se comporte de forma "adequada", o que pouco contribui para a formação humana integral, considerada, por um lado, a articulação entre a educação geral e a profissional e, por outro lado, a formação plena que possibilita ao educando a compreensão das partes no seu todo e as múltiplas mediações históricas que concretizam os processos educativos (CIAVATTA, 2014).

\section{CONSIDERAÇÕES FINAIS}

As normas disciplinares discentes do IFMA, em teoria, cumprem a função de regulamentar o comportamento dos educandos, destacando o que é permitido, o que é proibido e quais as punições em caso de desrespeito às regras. Com isso, ela orienta para cumprimento de horários, zelo pelo patrimônio público, uso de fardamento, preservação de meio ambiente, uso adequado do material didático, respeito para com as pessoas, dentre outros aspectos considerados importantes à boa convivência no ambiente escolar.

No entanto, a disciplina que busca contribuir para a formação humana integral do discente valoriza não as regras estabelecidas de forma unilateral, mas o diálogo, o contexto no qual os alunos estão inseridos, a autonomia, o autogoverno, e visa compreender os determinantes históricos dos comportamentos dos educandos, em lugar de fazer uso da punição, problematizando a realidade.

Além disso, é importante destacar que a disciplina em sala de aula precisa ser conduzida pelo docente, como autoridade do processo ensino- 
aprendizagem, assim como a indisciplina, a princípio, deve ser resolvida por ele também. Entretanto, o que se identificou nas normas foi a ausência do docente na mediação da indisciplina e a presença de outros profissionais da educação no tratamento da questão como pedagogos, psicólogos e diretores. Certamente o apoio desses profissionais é importante para o tratamento das questões disciplinares, mas não se deve perder de vista o caráter pedagógico da disciplina que é inerente à atividade docente.

Vale ressaltar, também, que a concepção de disciplina presente nas normas disciplinares do IFMA assemelha-se à concepção modeladora do século XVIII com ênfase na padronização, na vigilância e na punição tendo em vista a formação de sujeitos dóceis e úteis, como afirmava Foucault (1987). Tais docilidade e utilidade são convenientes aos interesses do grande capital que precisa de profissionais bem qualificados, do ponto de vista técnico e obedientes, do ponto de vista político, para acumular riqueza. Destaca-se, ainda, que essa concepção de disciplina é própria de um paradigma de educação tradicional, bancário que visa adaptar o indivíduo às necessidades do mercado de trabalho e à manutenção da realidade como está posta.

Respondendo à questão norteadora desse artigo sobre as contribuições das normas disciplinares discentes do IFMA para a formação humana integral, destaca-se que essas contribuições não foram identificadas nas normas analisadas e que estas possibilitam apenas o aprendizado de boas maneiras e o cumprimento de regras que visam à manutenção da ordem na Instituição, o que não é o objetivo da formação omnilateral, politécnica defendida por Marx, a qual tem como objetivo a educação intelectual, física e tecnológica dos sujeitos tendo em vista a compreensão e a transformação da totalidade social na qual estão inseridos. Nessa perspectiva, é importante que o Instituto Federal do Maranhão alinhe suas normas disciplinares discentes à sua intenção de formação humana integral se o seu objetivo for verdadeiramente a construção de uma sociedade mais justa e democrática.

\section{REFERÊNCIAS}

AQUINO, Júlio Groppa (org.). Indisciplina na escola: alternativas teóricas e práticas. 18. ed. São Paulo: Summus, 2016.

BRASIL. Lei № 11.892, de 29 de dezembro de 2008. Institui a Rede Federal de Educação Profissional, Científica e Tecnológica, cria os Institutos Federais de Educação, Ciência e Tecnologia, e dá outras providências. Disponível em: http://www.planalto.gov.br/ccivil_03/_Ato2007-2010/2008/Lei/L11892.htm. Acesso em: 09 dez. 2019.

BRASIL. Lei № 9394, de 20 de dezembro de 1996. Estabelece as diretrizes e bases da educação nacional. Disponível em:

http://www.planalto.gov.br/ccivil_03/leis/19394.htm. Acesso em: 01 dez. 2019. 
BRASIL. IFMA. Resolução № 032, de 03 de setembro de 2009. Aprova, ad referendum do Conselho Superior, as Normas Internas para uso de Uniforme escolar pelos alunos matriculados no Instituto Federal de Educação Ciência e Tecnologia do Maranhão. Disponível em:https://portal.ifma.edu.br /documentos/?categoria=1\&busca=RESOLU. Acesso em: 01 dez. 2019.

BRASIL. IFMA. Resolução № 009, de 10 de fevereiro de 2014. Aprova, ad referendum ao Conselho Superior, alteração no Anexo da Resolução 126/2013, que trata do Regimento Disciplinar Discente do Instituto Federal, Ciência e Tecnologia do Maranhão. Disponível em: https://portal.ifma.edu.br/ documentos/?categoria=1\& busca=RESOLU. Acesso em: $01 \mathrm{dez} .2019$

BRASIL. IFMA. Resolução № 30, de 11 de junho de 2014. Dispõe acerca do Regimento Geral do Instituto Federal de Educação, Ciência e Tecnologia do Maranhão. Disponível em: https://portal.ifma.edu.br/documentos/ ?categoria=1\&busca=RESOLU. Acesso em: 01 dez. 2019.

CIAVATTA, Maria. O ensino integrado, a politecnia e a educação omnilateral: por que lutamos? Trabalho \& Educação, Belo Horizonte, v. 23, n. 1, p. 187205, 2014. Disponível em: https://periodicos.ufmg.br/index.php/trabedu/ article/view/9303. Acesso em: 10 out. 2019.

DANTE, Henrique Moura. Ensino médio integrado: subsunção aos interesses do capital ou travessia para a formação humana integral? Educação e Pesquisa, São Paulo, v. 39, n. 3, p. 705-720, 2013. Disponível em: http://www.scielo.br/scielo.php?pid=S1517-97022013000300010 \&script=sci_abstract\&tlng=pt. Acesso em: 10 out. 2019.

DANTE, Henrique Moura; LIMA FILHO, Domingos Leite; SILVA, Mônica Ribeiro. Politecnia e formação integrada: confrontos conceituais, projetos políticos e contradições históricas da educação brasileira. Revista Brasileira de Educação, v. 20, n. 63, 2015. Disponível em: http://www.scielo.brn /scielo.php?pid=S1413-24782015000401057\&script=sci_abstract\&tIng=pt Acesso em: 08 set. 2019.

FOUCAULT, Michel. Vigiar e punir: nascimento da prisão. Petrópolis: Vozes, 1987.

FREIRE, Paulo. Pedagogia da Autonomia: saberes necessários à prática educativa. 6. ed. São Paulo: Paz e Terra, 1997.

FREIRE, Paulo. Educação e Mudança. São Paulo: Paz e Terra,1979.

GRAMSCI, Antonio. Caderno 12. Os intelectuais. O princípio educativo. In: GRAMSCI, Antonio. Cadernos do Cárcere. Tradução de Carlos Nelson Coutinho. Rio de Janeiro: Civilização Brasileira, 2000.

LEITE, Priscila de Souza Chisté Leite. Contribuições do materialismo histórico dialético para pesquisas em Mestrados Profissionais na área de ensino de humanidades. CIAIQ. v. 1, p. 847-856, 2017. Disponível em:

https://proceedings.ciaiq.org/index.php/ciaiq2017/Article/view/1405/1362.

Acesso em: 28 out. 2019. 
LUDKE, Menga; ANDRÉ, Marli Eliza Dalmazo Afonso. Pesquisa em educação: abordagens qualitativas. 2 ed. Rio de Janeiro: E.P.U., 2018. MACÊDO, Francisco Cristiano da Silva; EVANGERLANDY, Gomes Macêdo. Pesquisa: passo a passo para a elaboração de trabalhos científicos. Teresina: Macêdo, F.C.S., 2018.

MANACORDA, Mario Alighiero. Marx e a pedagogia moderna. São Paulo: Alínea, 2007.

MARX, Karl. Instruções para os Delegados do Conselho Geral provisório: as diferentes questões. 1866. Editorial "Avante!", 1982. Disponível em: https://www.marxists.org/portugues/marx/1866/08/instrucoes.htm. Acesso em: 02 dez. 2019.

MINISTÉRIO DA EDUCAÇÃO. Histórico. Rede Federal, 2016. Disponível em: http://redefederal.mec.gov.br/historico. Acesso em: 02 dez. 2019.

PAULO NETTO, José. Introdução ao estudo do método de Marx. São Paulo: Expressão Popular, 2011.

PERCÍLIA, Eliene. Uniforme Escolar. Brasil Escola. Disponível em:

https://brasilescola.uol.com.br/volta-as-aulas/uniforme-escolar.htm. Acesso em: 02 dez. 2019.

RAMOS, Marise Nogueira. História e política da educação profissional. Curitiba: Instituto Federal do Paraná, 2014. (Coleção Formação Pedagógica, v. 5). Disponível em: https://curitiba.ifpr.edu.br/wp-content/uploads /2016/05/Hist\%C3\%B3ria-e-pol\%C3\%ADtica-da-educa\%C3\%A7\%C3\%A3oprofissional.pdf. Acesso em: 10 set. 2018

REBELO, Rosana Aparecida Argento. Indisciplina escolar: causas e sujeitos. 6. ed. Petrópolis: Vozes, 2011.

SAVIANI, Demerval. Pedagogia Histórico-Crítica. 11. ed. São Paulo: Autores Associados, 2013.

SEVERINO, Antônio Joaquim. Metodologia do trabalho científico. 24 ed. São Paulo: Cortez, 2016.

VASCONCELLOS, Celso dos Santos. Indisciplina e disciplina escolar: fundamentos para o trabalho docente. São Paulo: Cortez, 2009. 